\title{
Ice core-based isotopic constraints on past carbon cycle changes
}

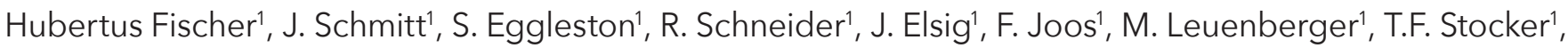 \\ P. Köhler ${ }^{2}$, V. Brovkin ${ }^{3}$ and J. Chappellaz
}

\begin{abstract}
High-precision ice core data on both atmospheric $\mathrm{CO}_{2}$ concentrations and their carbon isotopic composition $\left(\delta^{13} \mathrm{C}_{\text {atm }}\right)$ provide improved constraints on the marine and terrestrial processes responsible for carbon cycle changes during the last two interglacials and the preceding glacial/interglacial transitions.
\end{abstract}

$\mathrm{CO}_{2}$ represents the most important greenhouse gas released into the atmosphere as a result of human activity. The majority of our knowledge on the increase in $\mathrm{CO}_{2}$ since the start of the industrialization comes from ice cores, which complement the direct atmospheric $\mathrm{CO}_{2}$ measurements obtained at Mauna Loa since the 1950s. The combined $\mathrm{CO}_{2}$ record shows an unambiguous anthropogenic $\mathrm{CO}_{2}$ increase over the last 150 years from 280 to about 400 ppm in 2014. Values above $300 \mathrm{ppm}$ are unprecedented in the long-term ice core record covering the last 800,000 years with natural $\mathrm{CO}_{2}$ concentrations varying between interglacial and glacial bounds of about 280 and 180 ppm, respectively (Fig. 1; Lüthi et al. 2008; Petit et al. 1999). The record also showed that even during rather stable interglacial conditions, $\mathrm{CO}_{2}$ concentrations changed in response to long-term carbon cycle changes (Elsig et al. 2009). Although past atmospheric
$\mathrm{CO}_{2}$ concentrations are known with high precision, the causes of the preindustrial $\mathrm{CO}_{2}$ changes cannot be easily attributed to individual processes. Substantial progress could come from better estimates of past changes in the carbon stored by the biosphere or from using stable carbon isotopes to constrain sources and sinks of carbon and exchange processes with the atmosphere.

The vast majority of the carbon cycling in the Earth system on multi-millennial timescales resides in the ocean. Accordingly, the global $\delta^{13} \mathrm{C}$ of inorganic carbon dissolved in seawa$\operatorname{ter}\left(\delta^{13} C_{D I C}\right)$ may provide the best constraint on past carbon cycle changes. However, a global compilation of $\delta^{13} C_{D I C}$ from marine sediment records is hampered by insufficient spatial representation of vast ocean regions, the limited temporal resolution of many sediment records, and substantial chronologic uncertainties. The alternative,

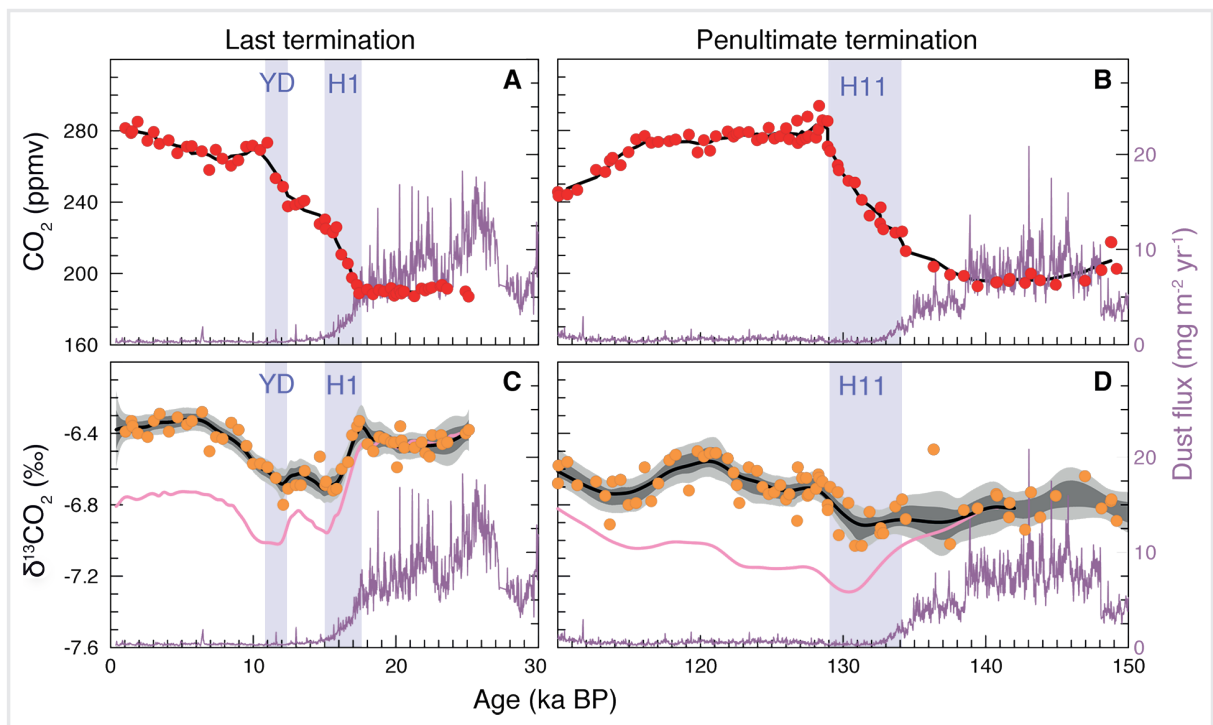

Figure 1: Evolution of atmospheric $\mathrm{CO}_{2}$ (red dots), $\delta^{13} \mathrm{CO}_{2}$ (orange dots), and dust flux (purple line) over the last two glacial/interglacial transitions and the subsequent interglacial periods. All measurements were performed on the EPICA Dome C ice core. The dark and light grey shaded fields represent the $1 \sigma$ and $2 \sigma$ errors of a Monte Carlo spline average of the $\delta^{13} \mathrm{CO}_{2}$ (black line; Schmitt et al. 2012; Schneider et al. 2013). The pink line indicates the $\delta^{13} \mathrm{C}_{\mathrm{atm}}$ spline after a first order correction for global sea surface temperature changes. High-resolution eolian dust fluxes (purple line; Lambert et al. 2012) provide a measure for Southern Ocean Fe fertilization. YD =Younger Dryas, $\mathrm{H}=$ Heinrich events. to reconstruct the mean $\delta^{13} \mathrm{C}$ record of the well-mixed atmosphere $\left(\delta^{13} \mathrm{Catm}\right)$ from the fossil air contained in Antarctic ice cores, has been a long-standing quest. Latest analytical progress that improved the measurement error while at the same time cutting down sample size by an order of magnitude has allowed us to gain this information from ice cores with the required precision and temporal resolution.

\section{The enigma of glacial/interglacial $\mathrm{CO}_{2}$ changes}

The cause of the glacial/interglacial 80-100 ppm increase of atmospheric $\mathrm{CO}_{2}$ represents a long-standing question in paleoclimate research. Several processes have been implied. These include Southern Ocean ventilation by wind or buoyancy feedbacks, iron fertilization of the marine biosphere in the Southern Ocean, changes in the re-mineralization depth of organic carbon, release of permafrost carbon during the deglaciation, decreased solubility due to ocean warming, changes in air/sea gas exchange due to changing sea ice cover, climate-induced changes in weathering changes rates, and marine carbonate feedbacks (Ciais et al. 2012; Fischer et al. 2010; Köhler and Fischer 2006; Menviel et al. 2012). However, none of these processes alone is able to explain the glacial/interglacial $\mathrm{CO}_{2}$ change.

Our new $\delta^{13} \mathrm{C}_{\mathrm{atm}}$ data from the air trapped in the Antarctic EPICA Dome C ice core, provide improved constraints to revisit the enigma of deglacial $\mathrm{CO}_{2}$ increase (Fig. 2). Mean $\delta^{13} \mathrm{C}_{\text {atm }}$ levels during peak glacials and interglacials were not much different, despite different $\mathrm{CO}_{2}$ concentrations and the substantially altered climate system. This implies that the $\delta^{13} \mathrm{C}_{\mathrm{atm}}$ record is the sum of several factors that balance each other to a large extent. For example, just considering the sea surface temperature-dependent fractionation of $\mathrm{CO}_{2}$ between the atmosphere and the ocean surface, approximately $0.4 \%$ lower $\delta^{13} C_{\text {atm }}$ values are expected for interglacials (Fig. 2). 

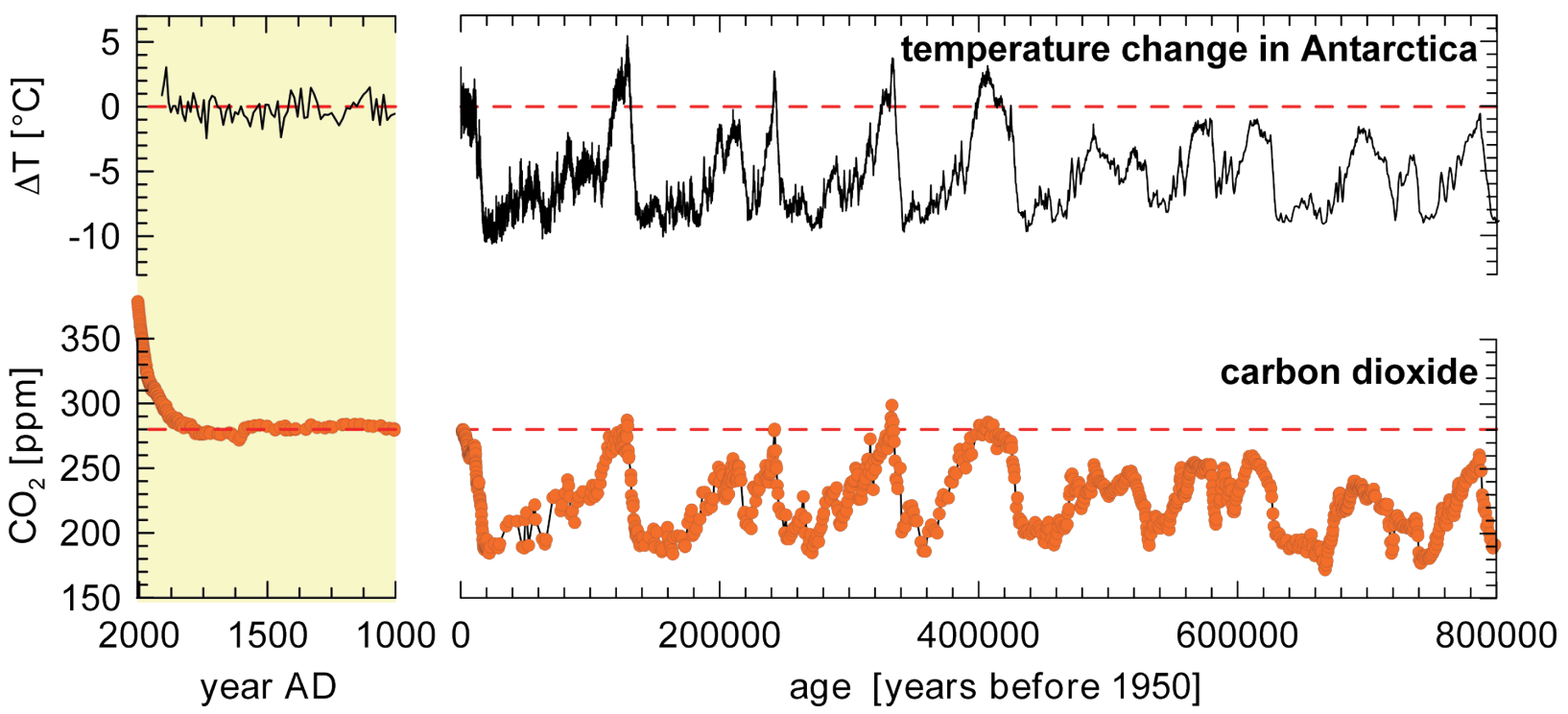

Figure 2: Right: Antarctic temperature and $\mathrm{CO}_{2}$ variations over the last 800,000 years. Ice sheet surface temperature change was calculated from $\delta D$ measured on the EPICA ice core from Dome C (EPICA community members 2004), $\mathrm{CO}_{2}$ concentrations were measured on the Antarctic Dome C and Vostok ice cores (Lüthi et al. 2008; Petit et al. 1999). Left: Blow up of Antarctic temperature (EPICA community members 2004) and $\mathrm{CO}_{2}$ concentration changes (MacFarling Meure et al. 2006) over the last 1000 years.

Our $\delta^{13} \mathrm{C}_{\text {atm }}$ data (Lourantou et al. 2010; Schmitt et al. 2012) from the last two major deglaciations suggest a sequence of processes that drove atmospheric $\mathrm{CO}_{2}$ changes during different stages of the transition from glacial conditions into a milder interglacial world.

- At the start of the transitions, upwelling of old ${ }^{13} \mathrm{C}$-depleted waters in the Southern Ocean increased the release of $\mathrm{CO}_{2}$ to the atmosphere. This process was likely synchronous with a demise in iron-stimulated bioproductivity in the Southern Ocean, when atmospheric dust concentrations declined rapidly.

- This was followed by the gradual growth of terrestrial carbon storage in vegetation, soil, and peatlands as evidenced by the slow $\delta^{13} \mathrm{C}_{\text {atm }}$ increase. This process reached well into the subsequent interglacials. Termination I was special in that it was interrupted by another upwelling event synchronous to the Younger Dryas in the Northern Hemisphere.

\section{The Holocene - natural changes or early anthropogenic influence?}

The Holocene is often described as a rather stable period in climate history. Nevertheless, from $7 \mathrm{ka}$ BP to the preindustrial era the $\mathrm{CO}_{2}$ concentration increased by $\sim 20$ ppm, i.e. by a quarter of the glacial/ interglacial change. Such a $\mathrm{CO}_{2}$ increase is not found during the preceding three interglacials (Marine Isotope Stage (MIS) 5.5, 7.5 or 9.3), although increases at similar rates can be found in MIS 11.3 or 15.5. This gave rise to the hypothesis that the Holocene $\mathrm{CO}_{2}$ increase may be unique and was caused by early anthropogenic land use (Ruddiman 2003). However, an anthropogenic release of isotopically light terrestrial carbon would lead to a decrease in $\delta^{13} \mathrm{C}_{\text {atm }}$ over the last 7000 years, which is not observed in our record (Fig. 2; Elsig et al. 2009). The expected anthropogenic $\delta^{13} C_{\text {atm }}$ decline could in principle have been compensated by a concurrent natural build-up of peat at higher latitudes, but in that case atmospheric $\mathrm{CO}_{2}$ should not have increased. In any case, a substantial early human influence on atmospheric $\mathrm{CO}_{2}$ is difficult to reconcile with the ice core evidence. Based on terrestrial carbon cycle model results (Stocker et al. 2011), anthropogenic land-use is also unlikely to have released sufficient carbon during the last 7000 years to explain the $20 \mathrm{ppm} \mathrm{CO}_{2}$ increase.

However, the carbon cycle may not only be altered by terrestrial processes during the Holocene, but also has a long-term ocean memory. The long-term carbonate compensation feedback (the re-equilibration of carbonate chemistry in the ocean) to carbon cycle changes occurring in the preceding deglaciation and enhanced shallow-water carbonate sedimentation during the Holocene due to sea level rise are acting on multi-millennial time scales and lead to a delayed increase in atmospheric $\mathrm{CO}_{2}$ as observed in the ice core record without changing $\delta^{13} \mathrm{C}_{\text {atm }}$ (Elsig et al. 2009; Kleinen et al. 2010; Menviel and Joos 2012).

If so, why is there no similar $\mathrm{CO}_{2}$ increase observed during MIS 5.5? Explanations probably lie in the individual configuration of orbital forcing of each interglacial but also in the preceding deglacial history. For example the unique Younger Dryas event during Termination I may have disturbed the deglacial carbon cycle re-adjustment.

\section{Outlook}

The examples shown from the last two glacial-interglacial transitions demonstrate the value of high-quality $\delta^{13} C_{a t m}$ data from Antarctic ice cores. However, maximum insight into the past carbon cycle can only be gained from joint atmospheric, terrestrial, and marine carbon cycle information in combination with coupled carbon cycle models. A stringent test for our carbon cycle understanding will be a future "Oldest Ice" ice core covering the last $1.5 \mathrm{Ma}$, which would provide the history of $\mathrm{CO}_{2}$ and $\delta^{13} \mathrm{C}$ over the mid-Pleistocene Revolution, when the glacial/interglacial cyclicity changed from a 40,000 year period driven by obliquity changes of the Earth's axis to the well-known 100,000 year cycles in the later Quaternary.

\section{AFFILIATIONS}

'Climate and Environmental Physics, Physics Institute and Oeschger Centre for Climate Change Research University of Bern, Switzerland

${ }^{2}$ Alfred Wegener Institute, Helmholtz Centre for Polar and Marine Research, Bremerhaven, Germany ${ }^{3}$ Max Planck Institute for Meteorology, Hamburg, Germany

${ }^{4}$ UJF-Grenoble 1/CNRS, Laboratoire de Glaciologie et Géophysique de l'Environnement (LGGE), Grenoble, France

\section{CONTACT}

Hubertus Fischer: hubertus.fischer@climate.unibe.ch

REFERENCES

Ciais $P$ et al. (2012) Nat Geosci 5: 74-79

Elsig J et al. (2009) Nature 461: 507-510

EPICA community members (2004) Nature 429: 623-628

Kleinen T et al. (2010) Geophys Res Lett 37, doi:10.1029/2009GL041391

Lambert F et al. (2012) Clim Past 8: 609-623

Lourantou A et al. (2010) Global Biogeochem Cycles 24 doi:10.1029/2009GB003545

Lüthi D et al. (2008) Nature 453: 379-382

MacFarling Meure C et al. (2006) Geophys Res Lett 33, doi:10.1029/2006GL026152

Menviel L, Joos F (2012) Paleoceanography 27, do: 10.1029/2011PA002224

Menviel L et al. (2012) Quat Sci Rev 56: 46-68 Petit JR et al. (1999) Nature 399: 429-436 Ruddiman WF (2003) Climatic Change 61: 261-293 Schmitt J et al. (2012) Science 336: 711-714

Schneider R et al. (2013) Clim Past 9: 2507-2523

Stocker B et al. (2011) Biogeosciences 8: 69-88 